\title{
SIMULATING THE EFFECT OF DEPTH OF CUT AND FEED RATE ON THE FORCE COMPONENTS IN FACE MILLING
}

\author{
Mohammad Zaher Akkad \\ MSc student, Institute of Manufacturing Science, University of Miskolc \\ 3515 Miskolc, Miskolc-Egyetemváros, e-mail: zaherakkad91@gmail.com \\ Csaba Felhő \\ Associate professor, Institute of Manufacturing Science, University of Miskolc \\ 3515 Miskolc, Miskolc-Egyetemváros, e-mail: csaba.felho@uni-miskolc.hu
}

\begin{abstract}
This paper presents a study about the workpiece force components $(F x, F y, F z)$ changes in face milling, which results from changing the depth of cut and the feed rate values. The values of the three force components in the face milling operation were found through the FEA-software AdvantEdge by Third Wave Systems. This program is uniquely intended for modelling of cutting processes.

Simulations were carried out within five different cutting depth of cut and feed rate, to compare the obtained values and find out the results of the impact of changes on the three force components.
\end{abstract}

Keywords: Face milling, FEA simulation, cutting force component.

\section{Introduction}

Machining is one of the most expansively and effectively used part shaping methods. Competent models are needed for explaining the machining process accurately. Models are the scientific expectations of the machining process as reality, in terms of technical and industrial sides. Milling operations are the most common machining operations, which can be used in the industry. It is used for material removal, face finishing, edge finishing, etc. Several parameters can influence the acting forces on the cutting tool in milling. The forces may become unpredictable and result in larger dimensional because of those parameters [1].

In industrial practice, the increase in cutting speed has technical limitations especially with considering the value of the tool life; the machining tools have low tolerance in the revolutions number of the spindle. The feed rate increase is only made by choosing the appropriate tool geometry. With increasing the feed rate, the shape of the undeformed chip cross section $A_{c}$ also changes, which influences the cutting forces and the roughness of the machined surface. By increasing $f_{z}$ (feed per tooth), while using constant depth of cut $a_{p}$, the medium chip thickness $h_{m}$ increases and changes the $a_{p} / f_{z}$ ratio. Consequently, several cutting technical parameters are changed in addition to the cutting forces [2].

Face milling process is an important manufacturing process, which is always used. Identifying the force values that are used in this operation would help to optimise the parameters in this process, in order to reach the best values, which lead to get the best performance with the longest tool life.

The depth of cut and feed rate have a direct influence on the cutting forces in milling. Therefore, there were many investigations on their impact on the forces. Korkut and Donertas [3] found that the cutting forces are getting bigger by increasing the feed rate and depth of cut. Dikshit, et al. [4] found that the axial depth of cut is a dominant parameter that affects the tangential and radial forces and radial depth of cut has more influence on radial and axial cutting forces in comparing to feed per tooth. 
Akkad, M.Z., Felhö, Cs.

Simulating the effect of depth of cut and feed rate

Kadirgama, et al [5] found that the milling parameter axial depth, feed rate and cutting speed have an important influence on producing the high friction force, coefficient, angle and stress. Sequeira, et al. [6] found:

1. The depth of cut had a greater static influence followed by feed rate and spindle speed on workpiece cutting force component Fx.

2. The spindle speed had greater static influence followed by feed rate and depth of cut on workpiece cutting force component Fy.

3. The feed rate has greater static influence followed by the depth of cut and spindle speed on workpiece cutting force component Fz.

4. The feed rate has greater static influence followed by spindle speed and depth of cut on surface roughness.

\section{Methodology}

Two programs were used in order to get the results; AdvantEdge program to simulate the face milling operations and obtain the results and Tecplot 360 program to show the three force components and analyse them.

1. AdvantEdge

AdvantEdge is the premier Finite Element Analysis (FEA) product used to understand the metal cutting process. It is a powerful tool for designing, setting up, improving and optimizing machining processes. It enables users to determine machining parameters and tooling configurations that can reduce cutting forces, temperatures, and part distortion, all off-line. This reduces the need for testing, which costs money and valuable production time [7]. It was used in this research to simulate five face milling operations with different parameters for each one. The used AdvantEdge version is 7.3.

2. Tecplot 360

Tecplot 360 has a data visualization and post-processing tools help to discover, analyse and communicate complex data from numerical simulations. It was used in this research to show the resulted three force components Fx, Fy, Fz in both of the experiments and simulation.

\section{Simulation parameters}

For using the AdvantEdge program, many parameters are needed. Table 1 shows all the parameters, which were used for the five operations. A symmetrical arrangement was applied in the tests. Different depth of cut $a_{p}$ and feed per tooth $f_{z}$ values were used for each one of the five operations while the undeformed chip cross section was $A_{c}=0.1 \mathrm{~mm}^{2}$ in all cases. Table 2 shows $\mathrm{f}_{z}, a_{p}$ and $\mathrm{SV}$ for each operation. SV is a relation between the undeformed chip width $\mathrm{b}$ and the undeformed chip thickness $\mathrm{h}[8]$, it can be calculated as $\mathrm{SV}=\mathrm{a}_{\mathrm{p}} / \mathrm{f}_{\mathrm{z}}$.

It is noticed that No 4 and No 5 operations are made with inverse cutting technology since SV for them is less than one. Inverse cutting has some differences than the conventional cutting, where inverse cutting technology make:

1. Increase of the dynamic stability in the milling process by:

- Maximizing of passive force and its impact on the machine spindle.

- Minimizing of feed force and a decrease of radial tool defluxion.

2. Make gain in efficiency.

3. Make the optimisation of chip formation and chip flow [8]. 
Table 1. Simulation parameters

\begin{tabular}{|c|c|c|}
\hline Parameter name & Value & Unit \\
\hline Radial rake angle & -7 & degree \\
\hline Axial rake angle & 0.4 & degree \\
\hline Edge radius & 0.08 & $\mathrm{~mm}$ \\
\hline Tool width & 0.2 & $\mathrm{~mm}$ \\
\hline Number of teeth & 1 & tooth \\
\hline Cutting diameter & 68 & $\mathrm{~mm}$ \\
\hline Spindle speed & 986 & $\mathrm{rpm}$ \\
\hline Angle of rotation & 170 & degree \\
\hline Workpiece hardness & 236 & BHN \\
\hline Workpiece width & 59 & $\mathrm{~mm}$ \\
\hline Workpiece length & 50 & $\mathrm{~mm}$ \\
\hline Workpiece height & 50 & $\mathrm{~mm}$ \\
\hline Workpiece material & Steel C45 & 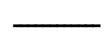 \\
\hline
\end{tabular}

Table 2. Operation parameters

\begin{tabular}{|c|c|c|c|c|c|}
\hline Operation No & $1 \mathrm{st}$ & $2 \mathrm{nd}$ & $3 \mathrm{rd}$ & 4 th & 5 th \\
\hline $\mathrm{a}_{\mathrm{p}}$ & 1 & 0.5 & 0.316 & 0.2 & 0.1 \\
\hline $\mathrm{f}_{\mathrm{z}}$ & 0.1 & 0.2 & 0.316 & 0.5 & 1 \\
\hline $\mathrm{SV}$ & 10 & 2.5 & 1 & 0.4 & 0.1 \\
\hline
\end{tabular}

The simulation process may take a long time depending on the used computer specifications. The first simulation process took eight days to be done. After the simulation is done, the results can be obtained by using Tecplot 360 program, which was used to obtain the results of the experiments previously. AdvantEdge software applies a simulation for the face milling operation. Figure 1 shows an illustration for the cutting simulation, it shows the insert tool simulation while it cuts the workpiece. 


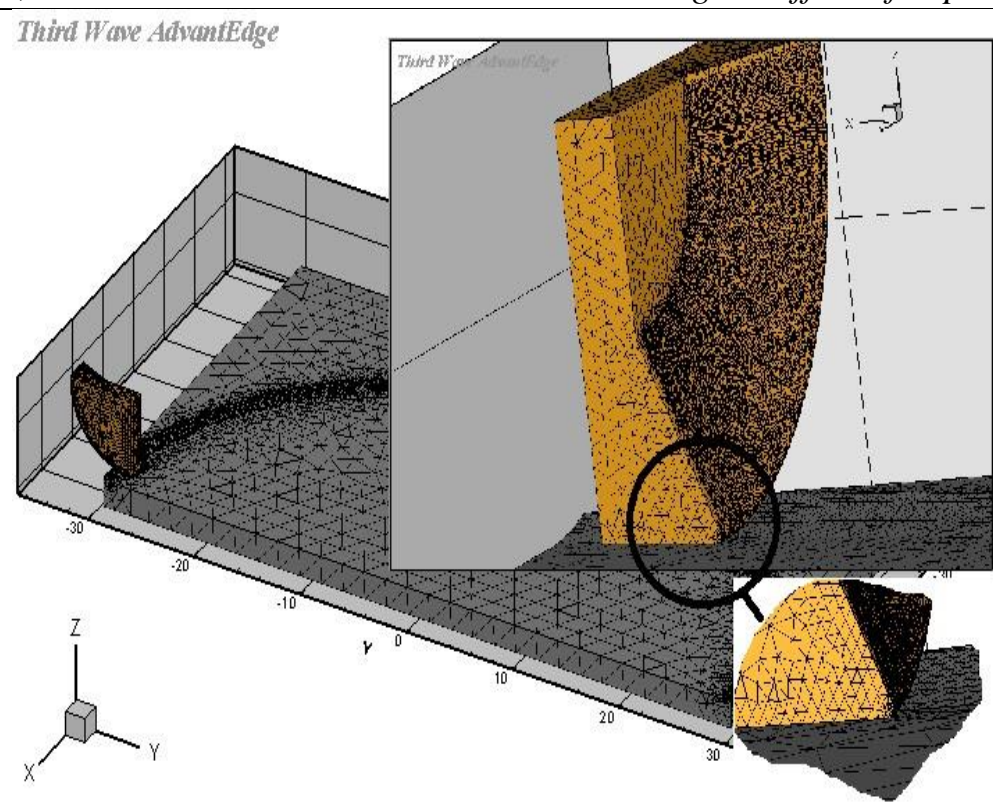

Figure 1. AdvantEdge simulation

\section{Simulation results}

By using Tecplot 360 to show the resulted forces, it can be obtained as a graph for each simulation operation. The graph can be opened directly from AdvantEdge software or from Tecplot software by using Quick Analyser and choosing the wanted result. The graph shows one cutting period for each operation. Figure 2 shows the resulted graph for the simulated first operation.

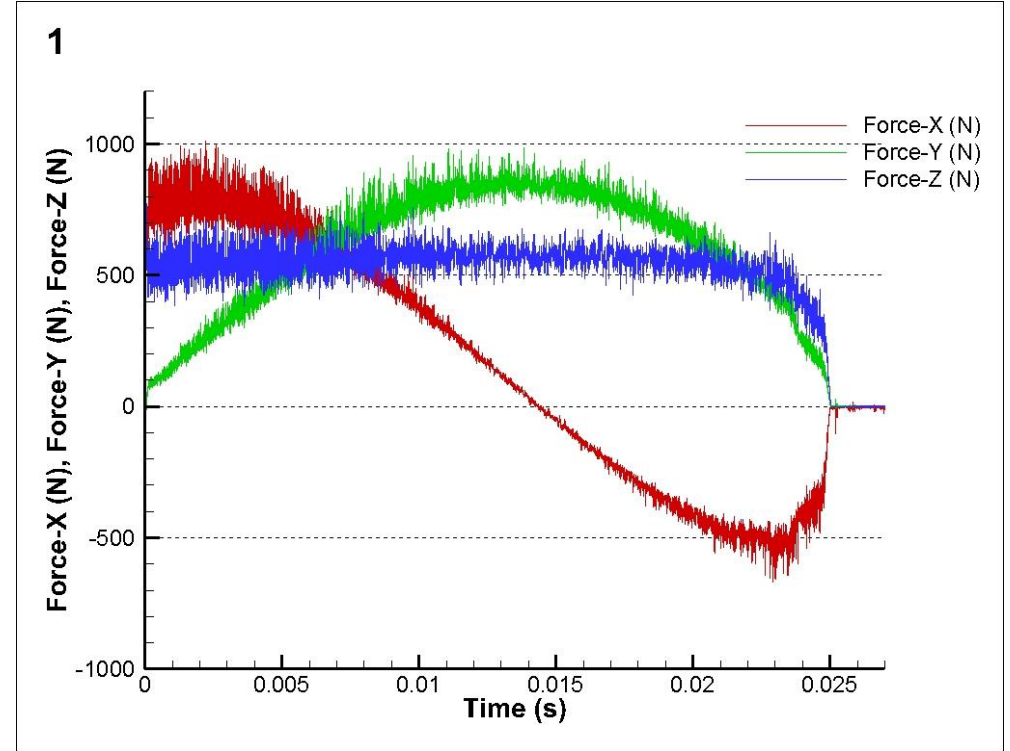

Figure 2. Original first simulation operation graph 
The simulation curve is not clear and it has a big distortion. One of the options in Tecplot is changing the curve type. Therefore, the curve type was changed to have more clear curves from Line Segment type to Polynomial Fit type.

By applying the new curve type, the new resulted graph appears, Figure 3.

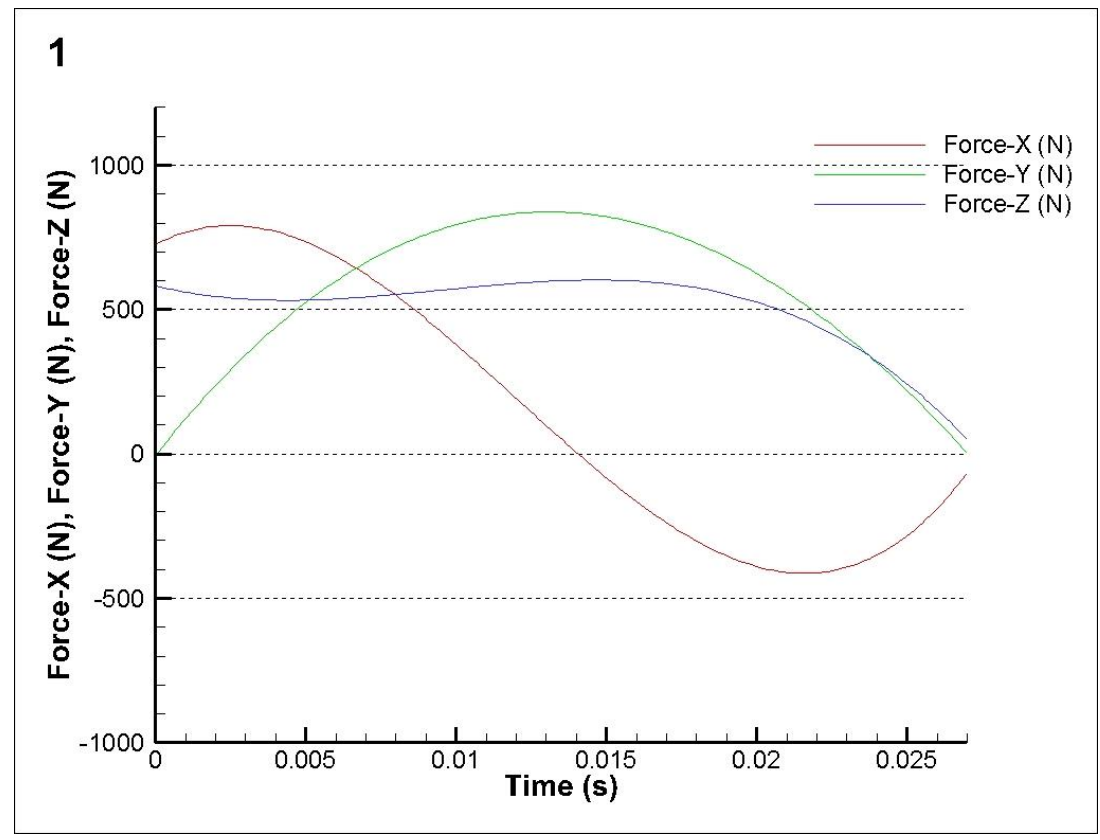

Figure 3. First simulation operation graph

Different changes can be noticed for each one of the forces. Fx has increasing at the beginning of the cutting period then decreasing until reaching negative value at the end of the cutting period but the positive value for Fx stays bigger than the negative one. Fy is the biggest value even it starts from zero, it has the same traditional Fy shape where it starts to increase to reach the maximum value then return to zero. Fz has less value changes and it stays in the positive area, it has the smallest maximum value among the three forces. The curves show similar shape and characteristics to the traditional round insert results. For the other operations, from second to fifth, Figure 4 shows the resulted graphs.

The second operation has almost the same characteristics of the first one with slight changes in the forces into bigger values. Fx has the conventional curve where it increases to reach more than $900 \mathrm{~N}$ then decreases to the negative value to reach almost $-600 \mathrm{~N}$ then increases again to reach the zero value almost at the end. Fy starts from zero until it reaches the biggest value (more than $1000 \mathrm{~N}$ ) in the middle of the cutting period then it decreases after the middle of the period to reach almost zero at the end. Fz starts with more than $800 \mathrm{~N}$ value almost than it is still almost stable until the end where it decreases to reach almost zero.

The third simulation operation has almost the same characteristics of the previous operations with slight decreasing in the values of the force.

The fourth simulation operation has a big decreasing in the values of Fx and Fy but Fz has just a slight decreasing.

The fifth simulation operation shows huge decreasing in the values of Fx and Fy while Fz has a slight change in its value. That makes Fz has the biggest value among the three force components, 
Akkad, M.Z., Felhö, Cs.

Simulating the effect of depth of cut and feed rate which in line with previous studies on the inverse cutting technology [8]. The inverse cutting is resulted in changing the feed rate and the depth of cut values.
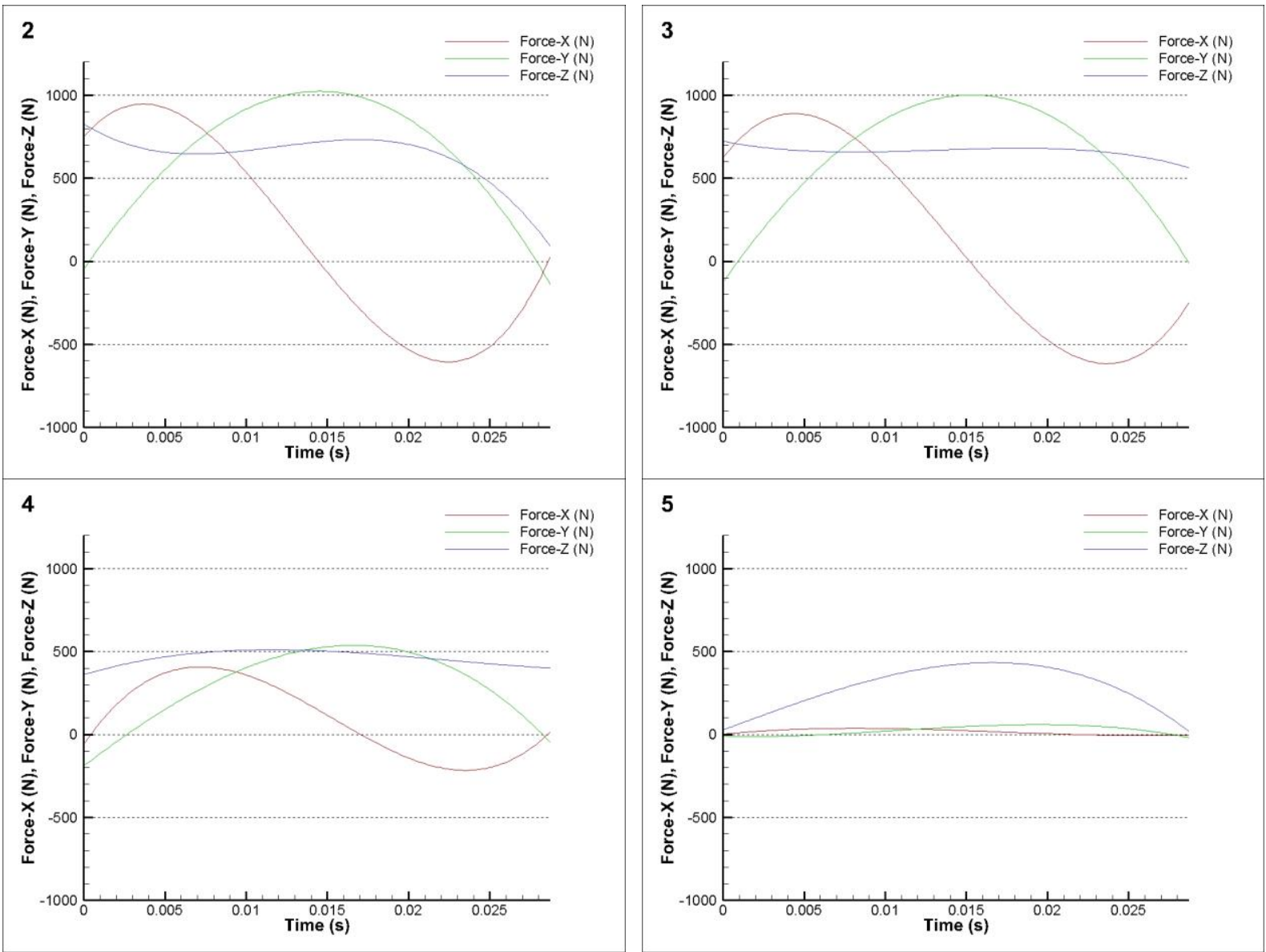

Figure 4. Second to fifth simulation operation graphs

The maximum forces values for the five simulation operations are summarized in Table 3.

Table 3. Max forces values $(N)$

\begin{tabular}{|c|c|c|c|c|c|}
\hline Operation No & 1 st & 2nd & 3rd & 4 th & 5 th \\
\hline Fx & 789 & 948 & 882 & 406 & 37 \\
\hline Fy & 836 & 1026 & 1005 & 537 & 60 \\
\hline Fz & 606 & 826 & 723 & 512 & 433 \\
\hline
\end{tabular}

The first and second operations use a conventional cutting method since SV for them is more than one while the fourth and fifth operations use inverse cutting technology since SV for them is less than one. 
Akkad, M.Z., Felhö, Cs.

Simulating the effect of depth of cut and feed rate

Figure 5 illustrates the force components changes from an operation to another. There are two different characteristic areas depending on SV value. Firstly, from 10 to 1, where the forces are increasing slightly until they stabled, since the increasing of feed rate increases the values of the force while the decrease of depth of cut decreases the values of the force, it appears that the feed rate has a stronger influence on the forces in this area, which makes the values of the force bigger. Secondly, from 1 to 0.1 , where the forces Fx and Fy are decreasing significantly while Fz has less decreasing, which makes Fz the biggest force among the three components, it appears that the depth of cut has a stronger influence on the forces change than the feed rate. Therefore, we can consider that the cutting parameters affect the three force components Fx, Fy, Fz values directly but that effect is related to the cutting method, whether it is conventional or inverse technology.

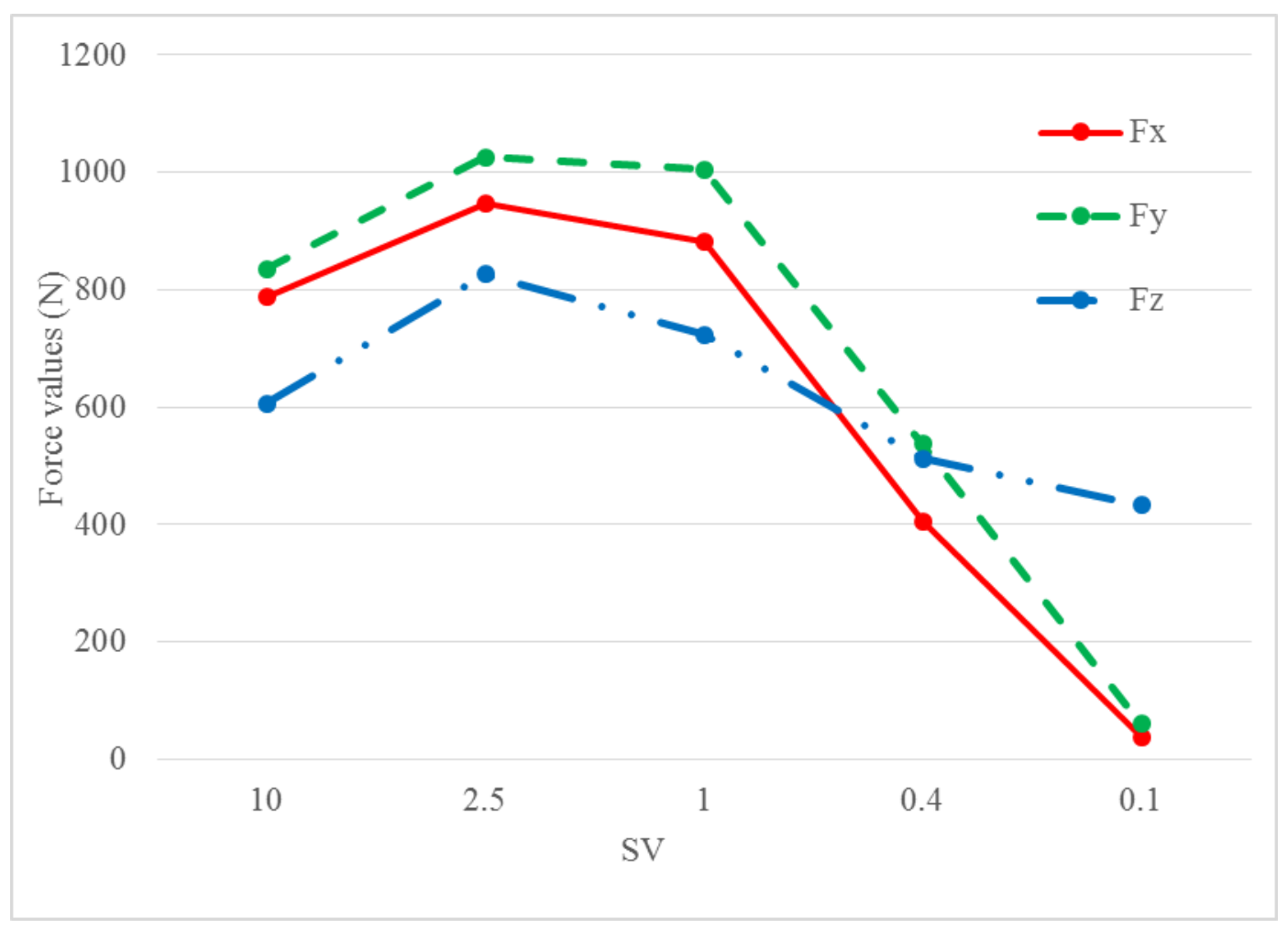

Figure 5. $F x, F y, F z$ changes

\section{Summary}

The simulation study showed different response to decrease the depth of cut $a_{p}$ and increase the feed per tooth $\mathrm{f}_{\mathrm{z}}$ where it was related to $\mathrm{SV}$ value whether it is conventional cutting (more than one) or inverse cutting (less than one). In the conventional cutting, the force components are increasing by the decrease of SV value. In the inverse cutting, the force components are decreasing by the decrease of SV value. This should be taken into consideration when using high feed rate in face mailing, to aim to work in inverse cutting conditions in order to be required fewer forces values, which may result in less power consumption for the used machine, more stability during the milling and longer tool life. 


\section{Acknowledgement}

The authors greatly appreciate the support of the National Research, Development and Innovation Office - NKFIH (No. of Agreement: OTKA K 116876).

The described paper was carried out as part of the EFOP-3.6.1-16-2016-00011 "Younger and Renewing University - Innovative Knowledge City - institutional development of the University of Miskolc aiming at intelligent specialisation" project implemented in the framework of the Szechenyi 2020 program. The realization of this project is supported by the European Union, co-financed by the European Social Fund.

\section{References}

[1] Kundrák, J., Makkai, T., Deszpoth, I., Nagy, A.: Investigation of Cutting Force in Face Milling, Rezanie i Instrumenty v Tekhnologicheskih Sistemah 87 (1) (2017) pp.118-125.

[2] Kundrák, J., Markopoulos, A.P., Makkai, T., Deszpoth, I., Nagy, A.: Analysis of the effect of feed on chip size ratio and cutting forces in face milling for various cutting speeds, Manufacturing Technology, 18(3), (2018) pp.431-438. https://doi.org/10.21062/ujep/117.2018/a/12132489/MT/18/3/431

[3] Korkut, I., Donertas M.A.: The influence of feed rate and cutting speed on the cutting forces, surface roughness and tool-chip contact length during face milling, Materials and Design 28 (2007) pp.308-312. https://doi.org/10.1016/j.matdes.2005.06.002

[4] Dikshit, M.K., Puri, A.B., Maity, A. and Banerjee, A.J.: Analysis of cutting forces and optimisation of cutting parameters in high ball-end milling using response surface methodology and genetic algorithm, Procedia Materials Science 5 (2014) pp.1623-1632. https://doi.org/10.1016/j.mspro.2014.07.350

[5] Kadirgama, K., Noor, M.M., Rahaman, M.M., Abou-El-Hossein, K.A., Mohammad, B. and Habeeb, H.: Effect of milling parameters on frictions when milling Hastelloy C-22HS: A FEM and statistical method, Applied Sciences Research, 4. (2019) pp.216-228. https://doi.org/10.3923/tasr.2009.216.228

[6] Sequeira, A.A., Prabhu, R., Sriram, N.S. and Bhat, T.: Effect of cutting parameters on cutting force and surface roughness of aluminium components using face milling process - a Taguchi Approach, Journal of Mechanical and Civil Engineering 3(4) (2012) pp.07-13. https://doi.org/10.9790/1684-0340713

[7] Third Wave Systems: AdvantEdge 7.1, User's manual.

[8] Karpuschewski, B., Kundrák, J., Emmer, T., Borysenko, D.: A new strategy in face milling - inverse cutting technology, Solid State Phenomena, 261 (2017) pp.331-338. https://doi.org/10.4028/www.scientific.net/SSP.261.331 